\title{
Ultrasonography of the ovaries and uterus and grey scale analysis of the endometrium during embryonic diapause in European roe deer
}

\author{
Robert HERMES, Thomas B. HILDEBRANDT, Frank GÖRITZ, \\ Katharina JEWGENOW, Thomas LENGWINAT and Reinhold R. HOFMANN
}

Hermes R., Hildebrandt T. B., Göritz F., Jewgenow K., Lengwinat T. and Hofmann R. R. 2000. Ultrasonography of the ovaries and uterus and grey scale analysis of the endometrium during embryonic diapause in European roe deer. Acta Theriologica 45: 559-572.

Knowledge about the mechanisms of embryonic diapause in European roe deer Capreolus capreolus (Linnaeus, 1758), although first described 140 years ago, is not extensive. In contrast to post mortem publications, this is an in-vivo study which monitored individual ovarian and uterine dynamics during diapause by transrectal ultrasonography. Ten roe deer were examined at 4 to 6 -week intervals starting from the end of the breeding season (August) until after implantation (January). Sonographic appearance of corpora lutea and their average number observed per animal did not differ between pregnant (3.6) and non-pregnant (3.2) does prior to implantation. However, in pregnant animals $(n=5)$ endometrial changes associated with embryonic diapause were identified. The endometrium in pregnant does were low in echogenicity compared to the non-pregnant. Changes in echogenicity of the endometrium were first detected three months before implantation. Observed endometrial changes were quantified by computer-assisted grey scale analysis. Mean medians of grey scale histograms were lower in pregnant compared to non-pregnant animals beginning as from October. In late December and January, embryonic structures were detected in animals in which a low echogenic endometrium had been observed earlier. Ultrasonography and grey scale analysis characterised efficiently the dynamic processes in the uterus and ovary during embryonic diapause in pregnant and non-pregnant roe deer.

Institute for Zoo Biology and Wildlife Research, Alfred-Kowalke-Str. 17, 10315 Berlin, Germany, e-mail: Hermes@IZW-Berlin.de

Key words: Capreolus capreolus, ultrasonography, diapause, grey scale analysis

\section{Introduction}

Embryonic diapause has been described in more than 115 species of seven mammalian orders (Marsupialia, Insectivora, Chiroptera, Edentata, Carnivora, Rodentia and Artiodactyla) (Mead 1993, Hermes 1998). Roe deer Capreolus capreolus (Linnaeus, 1758) is the only artiodactyl species that has developed the obligatory embryonic diapause as an reproductive strategy, which was discovered over 140 years ago (Ziegler 1843, Bischoff 1854, Short and Hay 1966). The monoestrous roe deer breeds from mid-July to early August. Conception is followed 
by a five month period of delayed implantation. Blastocyst development during this period is not fully inhibited, but extremely retarded. Implantation occurs at the end of this period in late December. Fawns are born from late April until early June, at a time when in Eurasia nutritional needs for lactation are best met by lush new vegetation.

During the period of embryonic diapause, both pregnant and non-pregnant does develop corpora lutea (CL) that do not differ in size or micro-structure (Aitken et al. 1973, Horak 1989). Initial progesterone concentrations in pregnant and non-pregnant does are similar and increase in pregnant deer only following implantation in mid-January (Aitken 1974, Hoffmann et al. 1978, Sempéré et al. 1989). Morphological studies of the uterus described uterine stromal tissue becoming oedematous during mating and subsiding shortly thereafter. The epithelium of the uterus decreases in height throughout the period of delayed implantation. The elongation of the trophoblast at the end of diapause appears to be correlated with the secretion of accumulated secretory vesicles of the epithelial cells of the endometrium (Keibel 1902, Hamilton et al. 1960, Short and Hay 1966, Aitken et al. 1973). To date, all morphological studies of the roe deer ovaries and uteri have used post-mortem material. While valuable information has been gained, this approach is not able to evaluate dynamic changes that occur during embryonic diapause.

Objective of this sonographic study was to monitor ovarian and uterine morphological changes during embryonic diapause in roe deer with different pregnancy status. Regular transrectal ultrasonographic examinations were to answer if number, sonographic appearance and dynamic of individual CL changes throughout diapause and if these characteristics are related to the pregnancy status of the female. Can structural changes of the endometrium during embryonic diapause in pregnant does (Aitken 1974) be identified by transrectal ultrasound and do endometrial changes also occur in non-pregnant does during this period?

\section{Material and methods}

\section{Animals}

Ten adult female roe deer housed at the field research station of the Institute for Zoo Biology and Wildlife Research at Niederfinow, Germany $\left(52^{\circ} 44^{\prime} \mathrm{N}, 13^{\circ} 50^{\prime} \mathrm{E}\right)$ and in Czempiń, Poland (5 $2^{\circ} 8^{\prime} \mathrm{N}$, $16^{\circ} 52^{\prime} \mathrm{E}$ ) were examined by transrectal ultrasound. Animals at Niederfinow (wild born) were housed in 2 groups of 4 individuals each in 1000 to $2000 \mathrm{~m}^{2}$ enclosures. Two animals housed in Czempir were managed individually and were hand-reared. Out of 10 animals, only 5 had access to a male during the breeding season, 4 in Niederfinow, 1 in Czempiń. Investigations commenced at the end of brieding season in August and were continued at 4 to 6 weeks intervals throughout the time of embyonic diapause, until the end January of the following year.

All animals were anaesthetised [ $2.0 \mathrm{mg} / \mathrm{kg}$ xylazine hydrochloride (Rompun, Bayer, Germany) plus $4.0 \mathrm{mg} / \mathrm{kg}$ ketamine hydrochloride (Ketamin, Albrecht, Germany)] via i.m. injection using a blow pipe. To reduce the interval between darting and recumbency, 150 I.U. hyaluronidase (Hylase ${ }^{\circledR}$, Imfstoffwerk Desssau, Germany) was added. To ensure acoustic coupling of the transrectally inerted ultrasound probe, an enema was given prior to each examination. After the 10-15 min tranrectal ultrasound examination, the xylazine effect of the anaesthesia was reversed by i.v. injection of 0.3 $\mathrm{mg} / \mathrm{kg}$ yohimbine (Caleo, Germany). 


\section{Ultrasonography}

Prior to the presented in vivo examinations 17 urogenital tracts were examined post-mortem in situ and ex situ by transrectal ultrasound. The topographical position of the genital organs in relation to the rectally inserted ultrasound probe was determined. A special scan head adapter was designed to ensure optimal transrectal sonographic imaging. To further validate sonographic findings 34 uteri and 30 ovaries were isolated and examined by ultrasound in a water bath. The sonographic texture of the uterus, the ovarian parenchyma, corpus luteum and follicles in roe deer was identified and later confirmed by morphological preparation (Fig. 1).

A portable ultrasound machine (CS 9100, Physia, Neu-Isenburg, Germany) was used for the examinations, equipped with a small, curved, linear array $7.5 \mathrm{MHz}$ transducer designed for endo-sonographic applications. Since manual rectal manipulation of an ultrasound probe is not possible in the roe deer due to its small anatomical dimensions, a special scan-head-extension was designed into which the transducer was placed (Fa. Schnorrenberg, Berlin, Germany) (Fig. 1). The angled extension tip guaranteed optimal contact of the transducer's array surface to the rectal wall and therefore ensured ideal sonographic imaging of the entire genital tract. For retrospective analysis, all ultrasound examinations were recorded with a video-camera (9100 SVO-P, Sony) on S-VHS videotape (S-VHS Pro SE-240 N, Fuji). Structural measurements were first made during the examination using a caliper system integrated into the ultrasound machine, and more precisely, in retrospective analysis from recorded videotapes using an image analysing program (analySIS PRO 2.10.100, Soft-Imaging System $\mathrm{GmbH}$, Münster, Germany). With regard to the computer-assisted grey scale analysis of selected
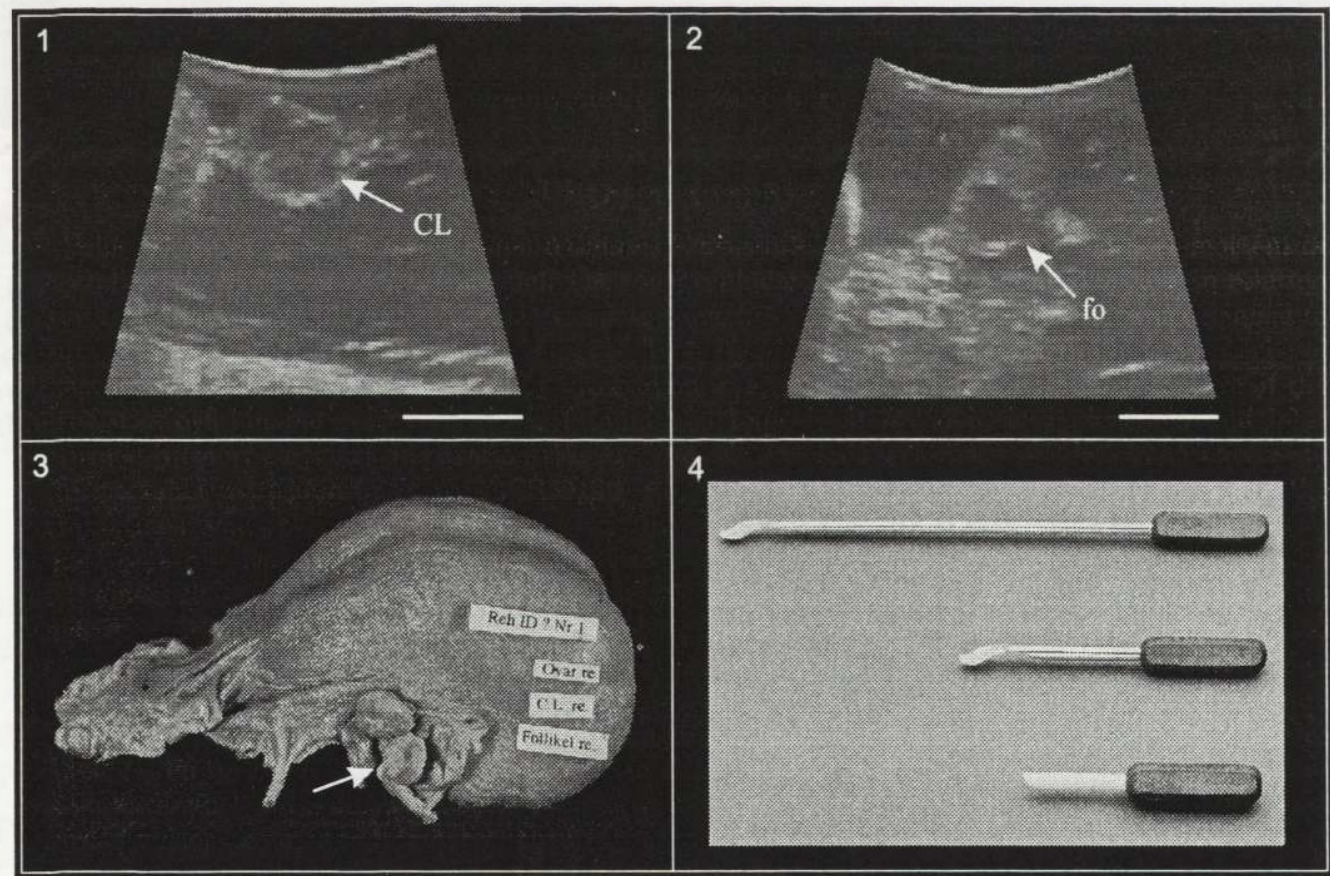

Fig. 1. Preliminary sonomorphologic study. (1) and (2) Post mortem sonograms of the ovary in the water bath. (1) Ovary with two medium echogenic corpora lutea (CL). (2) Anechoic follicle (fo) surrounded by ovary parenchyma. (3) Post mortem preparation of the female genital tract. The arrow indicates the cross section of the ovary. (4) Ultrasound probe adapters. Adapter length, diameter and tip angle were designed for optimised transrectal sonographic imaging in roe deer and other medium sized mammals. 
sonograms, ultrasound machine settings such as dynamic range (1 dB), enhancement (2), gain (35), focus (1-2), magnification $(50 \mathrm{~mm})$ and gamma correction (1) were kept constant throughout the study. The systematic examination of the vagina, cervix, uterus and ovaries included the exact positioning of the imaged organ within the focus zone 1-2 and the vertical centreline of the sonogram.

\section{Grey scale analysis}

For retrospective grey scale analysis of endometrial changes throughout the investigation, single video frames were digitised. Digitised sonograms were saved to external, removable cartridges (105MB/270MB, SyQuest Technology, Inc., Fremont, USA) for repeated analysis. The image analysing software (analySIS PRO 2.10.100, Soft-Imaging System GmbH, Münster, Germany) was configured to a monochrome signal of $0-255$ grey scales and 8 bit. Three sonograms of the uterus were digitised per animal at each examination. The position of the uterus within the sonogram was standardised in the focus zone 1-2 and the vertical centreline when digitised. This standard position of the uterus in the sonogram prevented influences on the echotexture of the endometrium which are caused by deviation from that position. The grey scale distribution of the endometrium was analysed by the placement of a region of interest $(\mathrm{ROI})$ into the endometrium. The small size of the ROI $(16 \times 16$ pixels) and its exact placement by the examiner ensured that myometrial and perimetrial tissue was excluded from the analysis. Placement of the ROI and subsequent analysis of endometrial grey scale distribution was performed on nine different locations of the uterine sonogram per examined animal per day. A median $( \pm$ SEM) was calculated for the 9 grey scale histograms. From these medians a mean median $( \pm$ SEM $)$ of grey scale histograms was calculated. Standardised settings of the ultrasound machine and exact positioning of the uterus in the focus zone 1-2 of the ultrasound beam ensured the comparability of uterine images of different roe deer throughout the period of examination.

\section{Results}

Adapted transrectal ultrasonography characterised changes in morphology of the ovaries and uterus of roe deer starting in August until visualisation of embryonic structures in pregnant deer in January (Figs 2, 3, 4, 5).

\section{Ovaries}

The ovaries were repeatedly imaged in all roe deer and characterised as spherical structures with dimensions of $12 \pm 5 \mathrm{~mm} \times 8 \pm 4 \mathrm{~mm}$ (Figs 1 and 2). The topographic position of the ovaries varied from cranio-dorsal of the uterine curvatura major and caudo-ventral of the uterine curvatura minor at a distarce of $10-30 \mathrm{~mm}$ from the rectal wall. Depending on the stage of the oestrous cycle, ovaries were characterised by a low to medium echogenic uniform parenchymal texture, expressing lower echogenic texture in August. The development of individual CL was monitored throughout the period of embryonic diapause in individual does of different pregnancy status (Fig. 3). Follicles were distinguished from the parenchyma as anechogenic round structures (Figs 1 and 2). The largest pre-ovulatory follicle observed was $4 \mathrm{~mm}$ in diameter. After ovulation round-oval shaped CL were detected where large antral follicles previously had been imaged. In September, shortly after the breeding period, CL were characterised by an echogenic margin and an anechogenic centre. The fully luteinised CL appeared low echogenic in comparison to the ovarian parenchyma. In contrast to anechogenic 


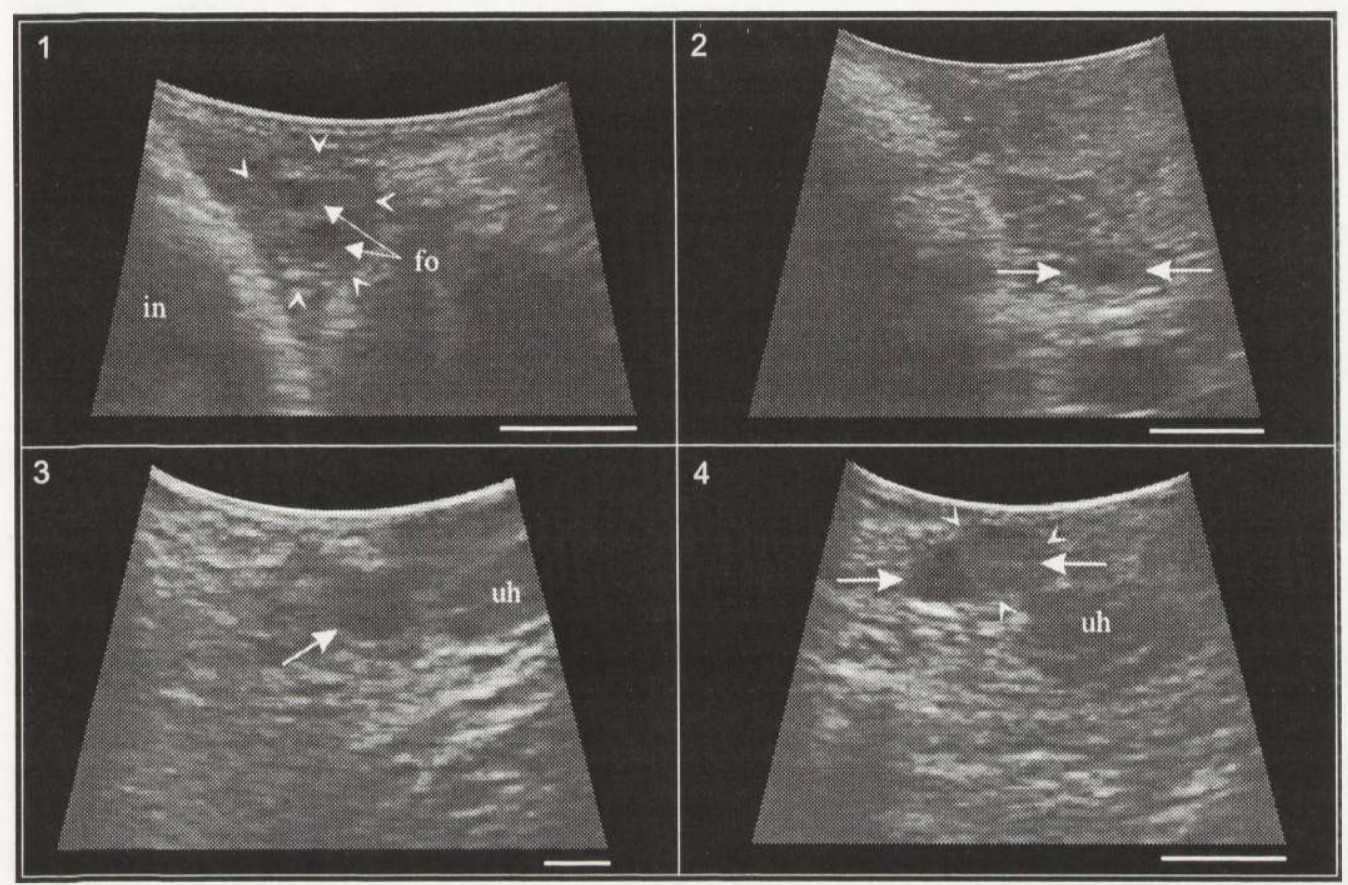

Fig. 2. Ultrasonographic images of ovaries during breeding season and embryonic diapause in roe deer: (1) Shortly before oestrous: anechogenic pre-ovulatory follicles (fo). Note high echogenic borderlines of the follicles. Intestinal loop (in) is located cranial to the ovary. (2) In September: corpus luteum ( $\leftarrow$ ) with echogenic margins and a still non-echogenic center. (3) and (4) From October corpora lutea appeared homogeneous without formation of margins $(\leftarrow)$. CL in a pregnant (3) and a non-pregnant (4) roe deer showed no differences in texture during embryonic diapause. Note that a similar texture of the uterine horn (uh) in (3) and (4) was carefully distinguished from the ovarian parenchyma.

large antral follicles, low echogenic CL did not show proximal and distal high echogenic lines caused from high impedance differences (Fig. 2).

CL in pregnant and non-pregnant deer did not show any difference in texture or cross-sectional diameter throughout the period of embryonic diapause (Table 1, Figs 2 and 3). Cross-sectional CL diameters ranged from 2.0 to $7.3 \mathrm{~mm}$ over the period of the study. Repeated imaging of individual CL showed variations in the cross-sectional diameter of up to $4 \mathrm{~mm}$ throughout the time of delayed implantation, changing on average $1.5 \mathrm{~mm}(n=32)$. Of all individual CL monitored throughout diapause $(n=34), 68 \%$ exhibited maximum diameters in November/ December independent from the pregnancy status. At the same time particular CL (16\%) were observed which had undergone regression while other CL of the same ovary remained unchanged in echogenicity. Regressive CL, which were characterised by increased echogenicity and decreased diameter, were detected at 
Table 1. Ovarian dynamics in roe deer during diapause. ${ }^{\text {a }}$ pre-ovulatory follicles before oestrous $>4 \mathrm{~mm}$.

\begin{tabular}{lcc}
\hline Ovarian parameters & Pregnant deer $(n=5)$ & Non-pregnant deer $(n=5)$ \\
\hline Number of CL observed & 18 & 16 \\
Number of CL per animal & 3.6 & 3.2 \\
Range of CL per animal & $2-6$ & $2-4$ \\
Range of diameter in CL & $2.0-6.9 \mathrm{~mm}$ & $2.8-7.3 \mathrm{~mm}$ \\
Average change of diameter in individual CL & $1.4 \mathrm{~mm}$ & $1.3 \mathrm{~mm}$ \\
Month of maximum CL diameter & November/December & November/December \\
Number of regressive CL & 3 & 2 \\
Month when CL regression occurred & December/January & December/January \\
Largest follicle observed during diapause & $3 \mathrm{~mm}^{\mathrm{a}}$ & $3 \mathrm{~mm}^{\mathrm{a}}$
\end{tabular}

the end of delayed implantation period in both pregnant and non-pregnant does (Fig. 3).

The development of antral follicles during the period of diapause was noted in both pregnant and non-pregnant does but was observed not to exceed a size of $3 \mathrm{~mm}$. No ovulation or development of additional CL was observed in any of the animals between September and January. The number of 1.4 implanted embryos per animal (range 1-2) in January did not correlate with the detected number of 3.2 CL per animal (range 2-4) before implantation.

\section{Uterus}

Utilizing ultrasound, it was possible to visualise the entire uterus and to identify the different uterine wall components: perimetrium, myometrium and endometrium (Fig. 3). The perimetrium had a high echogenic line that clearly distinguished the outline of the uterine body and uterine horns from surrounding tissues and organs. The endometrium appeared as a central layer surrounded by the uniform and low echogenic myometrium.

The sonographic appearance of the endometrium in pregnant does changed throughout embryonic diapause. In August/September, the first two months of diapause, the medium echogenic echotexture of the endometrium did not differ between pregnant and non-pregnant roe deer. Attached endometrial layers in the centre of the longitudinal uterine sonogram were marked by a thin, high echogenic line. From October to the end of embryonic diapause, sonographic evidence of endometrial changes was found in all pregnant animals $(n=5)$ (Fig. 4). The echogenicity of the endometrium in pregnant animals was decreasing in comparison with non-pregnant animals. Free uterine fluid was not detected in either pregnant or non-pregnant animals. Pregnancies that were diagnosed in the embryonic diapause were all confirmed in late December and January by documentation of rapid embryonic development (Fig. 5). Initially, in late December, the elongated, fluid-filled trophoblast and the embryonic yolk sac $(1-2 \mathrm{~mm})$ were detected. Only 
Ovary

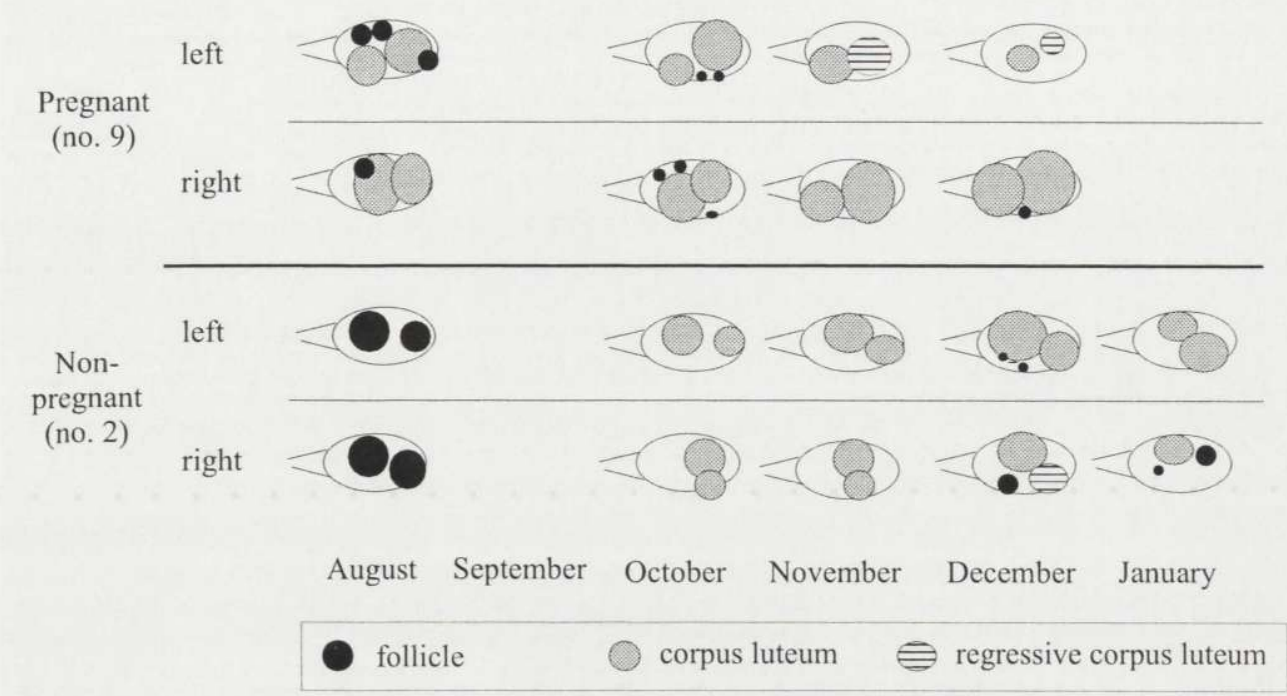

Fig. 3. Schematic ovarian dynamic of one non-pregnant (no. 2) and one pregnant (no. 9) roe deer. Pre-ovulatory follicles were detected in late rutting season. Individual corpora lutea were consistently imaged throughout diapause. Regression of individual corpus luteum was monitored in the pregnant and the non-pregnant doe only at the end of the diapause period in November/December.

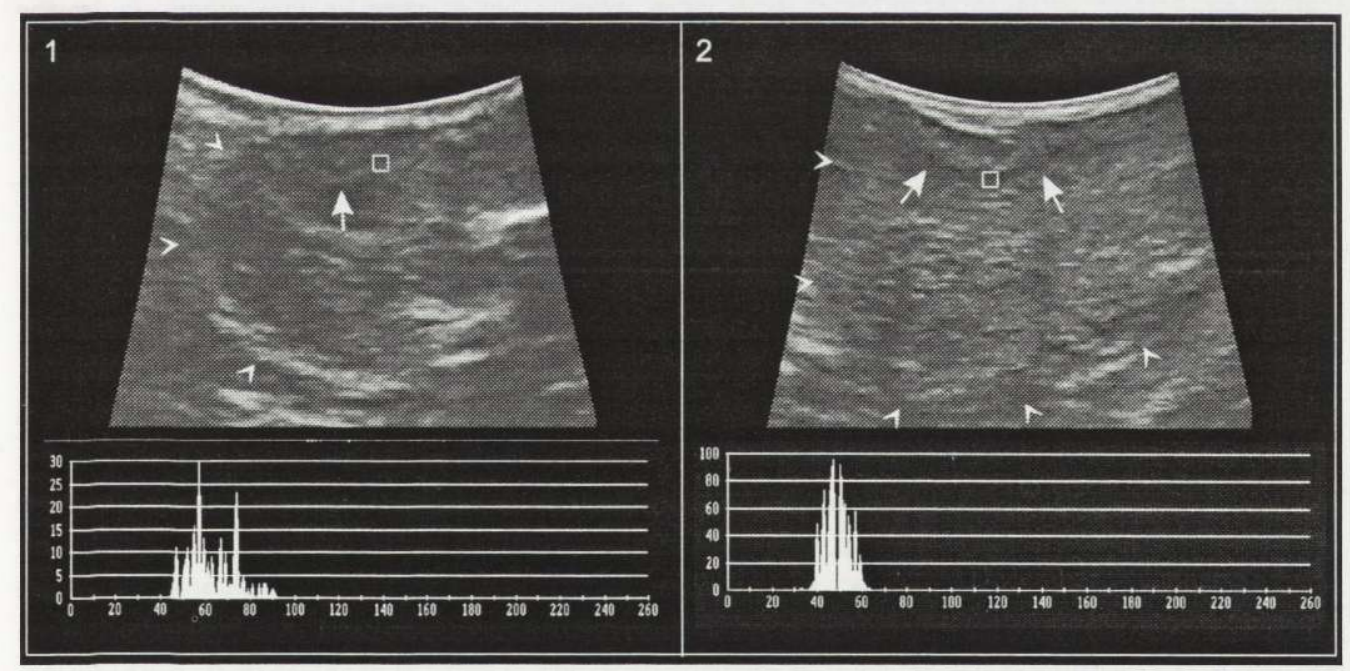

Fig. 4. Sonograms of the uterus $(<)$ and grey scale analysis of the endometrium in a non-pregnant (1) and a pregnant $(2)$ roe deer in December. The endometrium $(\leftarrow)$ of the non-pregnant animal was medium echogenic compared with the endometrium of the pregnant which was characterised by a low echogenic band in the centre of the longitudinal sonogram. Grey scale histograms from the region of interest $(\square)$ placed in the endometrium showed that darker grey scales dominated in the endometrium of the pregnant compared with a wider range of brighter grey scales in the non-pregnant animal. 


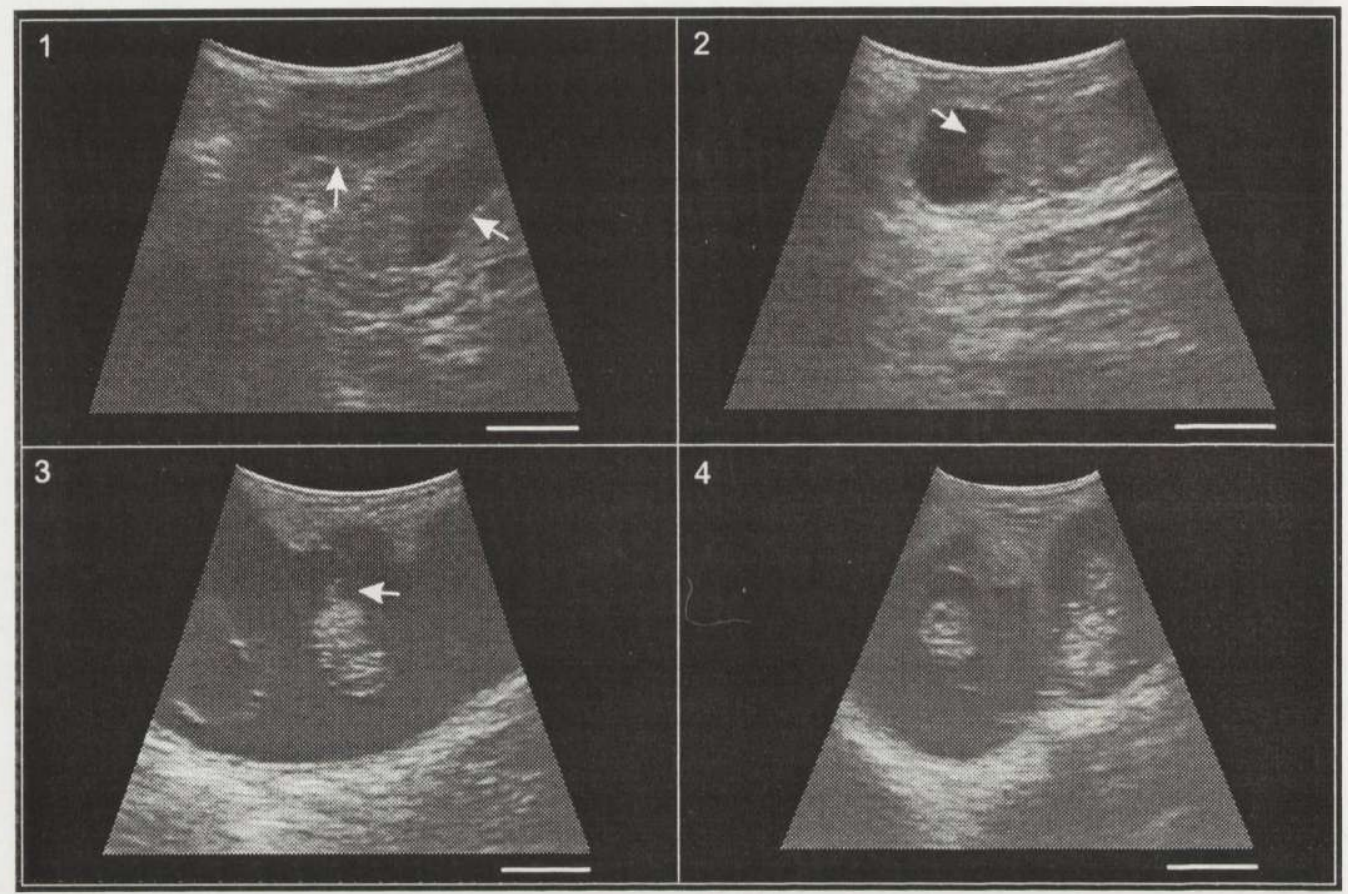

Fig. 5. Sonograms of embryonic development in roe deer following embryonic diapause: (1) The elongation of the trophoblast at the end of diapause was characterized in the sonogram by the chorio-allantoic vesicle $(\leftarrow)$. (2) Sonogram of a high echogenic yolk sac $(\leftarrow)$. (3) Further developed embryo with the umbilical cord $(\leftarrow)$. (4) Twin pregnancy.

10 days later, in the second week of January, embryos had a crown-rump-length of 8 and $8.5 \mathrm{~mm}$. The crown-rump-length in the last week of January averaged $29.1 \pm$ $5.8 \mathrm{~mm}(n=7)$.

\section{Grey scale analysis}

Quantification of endometrial texture by grey scale analysis characterised changes in pregnant and non-pregnant roe deer during embryonic diapause (Table 2, Figs 4 and 6). In August and September, mean medians of grey scale histograms from the endometrium in non-pregnant and pregnant roe deer were not different. In October, November and December mean medians of grey scale histograms were significantly lower in pregnant animals $(n=5)$ than in non-pregnant (Fig. 6). The grey scale values of the endometrium in pregnant animals in September however, were similar to those of pregnant animals in the following months. During the entire period of diapause mean medians of grey scale histograms in non-pregnant animals did not fall below 60.8 (September), whereas mean medians in pregnant animals as from September did not exceed the value of 52.9 (October). The characterised changes of the endometrium during diapause in pregnant roe deer 


$$
\frac{111 ! I}{\partial}
$$


were first detectable signs of pregnancy, which allowed the identification of pregnant does three months before the implantation of the trophoblast (Fig. 7).

\section{Discussion}

Ultrasonography is wildly used in several cervids for control of ovarian function, pregnancy detection and foetometry (Mulley et al. 1987, Bingham et al. 1990, Wilson and Bingham 1990, Revol and Wilson 1991, Lenz et al. 1993, Giżejewski et al. 1993, Hermes et al. 1996). In roe deer ultrasonography has previously been used to image embryonic structures in mid-January concurrent with the rise of progesterone levels after implantation (Sempéré et al. 1989). Previous studies showed the utility of using transrectal ultrasonography to visualise the reproductive tract in roe deer (Göritz et al. 1995, Hildebrandt et al. 1995). In these studies an optimised ultrasound technique combined with grey scale analysis clearly, and more objectively, documented changes in ovarian activity and the endometrium throughout the period of embryonic diapause.

Differing from other species in which an obligate embryonic diapause has been observed (Mustelidae: Mead 1989, Ursidae: Foresman and Daniel 1983, Pinnipedia: Boschier 1981), both pregnant and non-pregnant roe deer form CL that mainly contain large, plasma-rich granulosa-lutein cells (Short and Hay 1966, Aitken et al. 1973, Horak 1989). Thus corresponding to the CL histomorphology, the sonographic appearance of the CL in roe deer was low in echogenicity. Average number of CL per animal and sonographic characterisation of individual CL regression confirm earlier reports which have found no correlation between the number of CL and the number of implanted embryos in roe deer (Borg 1970, Horak 1989). Further in-vivo investigations will have to clarify whether embryonic death, as reported in sheep (Kaulfuss 1996), contributes to the miss correlation of CL numbers and numbers of implanted embryos in the roe deer. Thus in agreement with Borg (1970) and Horak (1989) it is concluded that CL counts from deceased animals cannot be used as a realistic basis for predicting population growth or recruitment rate in roe deer. Bettmann (1961) and more recently Stubbe (1997) have postulated a second mating period in November/December in roe deer which have not conceived in July/August, consequently defining the roe deer as dioestric and its obligate diapause as optional. These observations could not be supported by the present sonographic results: CL monitored in non-pregnant does in August were present throughout the entire diapause period. The regression of single CL was detected independent from the pregnancy status in November and December. Follicular development documented in pregnant and non-pregnant animals curing diapause was not observed to exceed the size of pre-ovulatory follicles detected at the end of rutting season. This data supports that the roe deer is a strictly monoestrous species in which non-pregnant animals exhibit anoestrous during the period of delayed implantation. Since a development of additional CL wes not observed either before or shortly after implantation, the reported progesterore rise 
after implantation (Hoffmann et al. 1978) is likely to originate in the placenta. This would be in contrast to the phylogenetically related red deer (Cervus elaphus) (Adam et al. 1985), where accessory CL are responsible for the rise in progesterone after implantation.

Although there were no differences in sonographic morphology of CL throughout embryonic diapause, morphological changes of the endometrium could be detected in pregnant animals only when compared with non-pregnant animals. The low echogenic appearance of the endometrium in the sonogram correlated with ultrastructural studies that described an accumulation of secretory vesicles in the epithelial cells of the endometrium during diapause (Aitken et al. 1973). The observed low echogenic endometrium in pregnant does was clearly differentiated from free uterine fluid. Since the uterine horns in roe deer are coiled similar to those in small ruminants, free uterine fluid would mainly have gathered in the ventral aspects of the uterine horns. Moreover, free uterine fluid would have been characterised by anechogenicity, high echogenic lines on the luminal-epithelial borders and inconsistency in lumen diameter upon manipulation of the uterus. The increase of darker grey scales in the texture of the endometrium of pregnant animals three months before implantation, however, was hardly visible for the examiner. The limited ability of the human eye to distinguish different grey levels (16-25) and to process visual information at a high speed explains that slight changes of echotexture in sonographic images can barely be recognised by the ultrasound examiner (Lieback-Zimmermann 1993). To overcome this limitation, grey scale analysis was developed and established in human cardiology, internal medicine, gynaecology and obstetrics. The objective assessment of sonographic changes in soft tissues is used for tumour characterisation in the thyroid gland, and mammary gland, for evaluating placental or foetal lung maturity, and for non-invasive diagnosis of cardiac rejection following heart transplantation (Morris 1988, Hirning et al. 1989, Sohn et al. 1992, Garra et al. 1993, Lieback et al. 1994). In this regard, grey scale distribution of the endometrium in roe deer of differing pregnancy status was quantifiable throughout embryonic diapause. One-dimensional grey scale analysis, used in humans to characterise changes in echocardiograms (Skorton et al. 1983, Fraker et al. 1988, Tak et al. 1988), was successfully used in this study to enhance the examiners limited visual capabilities. Mean medians from grey scale histograms of the roe deer endometrium were consistently low in pregnant animals, starting in September. Yet in September, differences of mean medians in pregnant and non-pregnant animals were not significant. The sonographic results indicate however that a combination of ultrasonography and grey scale analysis enables pregnancy diagnosis in roe deer 3 months before implantation, ie long before the elongation of the chorio-allantois vesicle is detectable in late December. Increased activity of the endometrial glands before implantation in pregnant roe deer as presented here and previously reported in an ultrastructural study (Aitken et al. 1973) indicates that the presence of an embryo induces initial maternal response. In the presented data, this endometrial response 
to conception was not found in non-pregnant animals. Although the embryo is responsible for a maternal response, the question whether the embryo or the female regulate the duration of diapause remains unanswered. The visualisation of embryonic structures in January proved the accuracy of sonographic pregnancy diagnosis during diapause in roe deer. During embryonic diapause in roe deer endometrial protein secretion and DNA-synthesis of the trophoblast cells remains low (Lengwinat and Meyer 1996, Lambert et al. 1998). Embryonic structures can not be detected by transcutaneous ultrasound before January (Sempéré et al. 1989), and progesterone- and oestrogen-levels rise only after implantation in January (Hoffmann et al. 1978). Ultrasonography combined with grey scale analysis described morphological changes of the pregnant uterus non-invasively, at a time pregnant and non-pregnant roe deer can not be distinguished by any other parameter. When integrated into future experimental investigations, transrectal ultrasonography, provides new opportunities to study in-vivo modifications during embryonic diapause.

Acknowledgements: The authors would like to thank J. L. Brown from the Smithsonian Institution for the assistance with this paper, M. Pinkowski, C. Baugatz, P. Baumann for the excellent animal management and A. Broich, S. Holz for the efficient technical assistance.

\section{References}

Adam C. L., Moir C. E. and Atkinson T. 1985. Plasma concentrations of progesterone in female red deer (Crevus elaphus) during the breeding season, pregnancy and anoestrous. Journal of Reproduction and Fertility 74: 631-636.

Aitken R. J. 1974. Delayed implantation in roe deer (Capreolus capreolus). Journal of Reproduction and Fertility 39: 225-233.

Aitken R. J., Burton J., Hawkins J., Kerr-Wilson R., Short R. V. and Steven D. H. 1973. Histological and ultrastructural changes in the blastocyst and reproductive tract of the roe deer, Capreolus capreolus, during delayed implantation. Journal of Reproduction and Fertility 34: 481-493.

Bettmann H. 1961. Winterbrunft beim Reh. Zeitschrift für Jagdwissenschaften 7: 169-170.

Bingham C. M., Wilson P. R. and Davies A. S. 1990. Real-time ultrasonography for pregnancy diagnosis and estimation of fetal age in farmed red deer. Veterinary Record 126: 102-106.

Bischoff T. L. W. 1854. Entwicklungsgeschichte des Rehes. Rickersche Buchhandlung, Gießen: 1-36.

Borg K. 1970. On mortality and reproduction of roe deer in Sweden during the period 1948-1969. Viltrevy 7: 121-149.

Boschier D. P. 1981. Structural changes in the corpus luteum and endometrium of seals before implantation. Journal of Reproduction and Fertility 29, Supplement 1: 143-149.

Foresman K. R. and Daniel J. C. 1983. Plasma progesterone concentrations in pregnant and nonpregnant black bears (Ursus americanus). Journal of Reproduction and Fertility 68: 235-239.

Fraker T. D., Bingle J. F., Wilkerson R. D., Klingler J. W., Weaver M. T. and Andrews L. T. 1988. Acute myocardial ischemia detected in dogs by temporal variation in two-dimensional ultrasound grey level. American Heart Journal 116: 249-253.

Garra B. S., Kranser B. H., Horii S. C., Ascher S., Mun S. K. and Zeman R. K. 1993. Improving the distinction between benign and malignant breast lesions: the value of sonographic texture analysis. Ultrasonic Imaging 15: 267-285.

Giżejewski Z., Pedich M., Jaczewski Z. and Bartecki R. 1993. Ultrasonic control of ovarian function in red deer females during oestrous cycle. [In: Deer of China: Biology and management. N. Ohtaishi and H.-I. Sheng, eds]. Elsevier Science Publihsers B.V., Amsterdam: 350-355. 
Göritz F., Hildebrandt T., Lengwinat T. and Meyer H. H. D. 1995. Ultrasound guided artificial insemination in roe deer (Capreolus capreolus). Reproduction in Domestic Animals 30: 460.

Hamilton W. J., Harrison R. J. and Young B. A. 1960. Aspects of placentation in certain cervidae. Journal of Anatomy 94: 1-33.

Hermes R. 1998. [Ultrasonography as a tool for monitoring pregnancy in roe deer (Capreolus capreolus) and quantification of endometrial echotexture during embryonic diapause using computer-assisted greyscale analysis]. Doctoral thesis, Freie Univiversität, Berlin: 1-119. [In German]

Hermes R., Hildebrandt T., Göritz F., Wiesenthal E. and Hofmann R. R. 1996. Transrektale Adaptersonographie zur Darstellung des weiblichen Genitaltraktes bei Europäischen Hirscharten (Capreolus capreolus, Cervus elaphus, Dama dama). Ultraschall 17: 80.

Hildebrandt T., Göritz F., Hermes R., Lengwinat T., Baugatz C., Pinkowski M. and Meyer H. H. D. 1995. Diagnosis of ovarian activity and pregnancy in roe deer (Capreolus capreolus) by transrectal sonography. Reproduction in Domestic Animals 30: 341.

Hirning T., Zuna I., Schlaps D., Lorenz D., Meybier H., Tschahargane C. and van Kaick G. 1989. Quantification and classification of echographic findings in the thyroid gland by computerized B-mode texture analysis. European Journal of Radiology 9: 244-247.

Hoffmann B., Barth D. and Karg H. 1978. Progesterone and estrogen levels in peripheral plasma of the pregnant and the nonpregnant roe deer (Capreolus capreolus). Biology of Reproduction 19: 931-935.

Horak A. 1989. Histologische und histomorphometrische Untersuchungen am Ovarium des Rehs (Capreolus capreolus, L.) und der zyklischen Veränderungen seiner Funktionsstrukturen. Ph D thesis, Justus-Liebig-Universität, Gießen: 1-146.

Kaulfuss, K.-H. 1996. Gynäkologische Ultrasonographie beim Schaf. Martin-Luther-Universität, Halle Wittenberg: 1-20.

Keibel F. 1902. Die Entwicklung des Rehes bis zur Anlage des Mesoblast. Archiv für Anatomie und Physiologie, Veit und Co. Press: 1-292.

Lambert R. T., Ashworth C. J., Beattie L., Gebbie F. E., Hutchinson J. S. M. and Racey P. A. 1998. Temporal changes in reproductive hormones and conceptus-endometrial interactions during delayed implantation in European roe deer. [In: Proceedings of the 4th International Deer Biology Congress, Koposvár, 30 June - 4 July 1998]. Pannon University of Agriculture, Koposvár: 448.

Lengwinat T. and Meyer H. H. D. 1996. Investigations of BrdU incorporation in roe deer blastocysts in vitro. Animal Reproduction Science 45: 103-107.

Lenz M. F., English A. W. and Dradjat A. 1993. Real-time ultrasonography for pregnancy diagnosis and foetal ageing in fallow deer. Australian Veterinary Journal 70: 373-375.

Lieback E., Meyer R., Nawrocki M., Bellach J. and Hetzer R. 1994. Noninvasive diagnosis of cardiac rejection through echocardiographic tissue characterization. Annals of Thoracic Surgery 57: 1164-1170.

Lieback-Zimmermann E. 1993. Computergestützte sonographische Gewebedifferenzierung des Myokards. [In: Fortschritte der Herz-, Thorax- und Gefächirurgie. R. Hetzer, ed]. Steinkopff Verlag, Darmstadt: 1-218.

Mead R. A. 1989. The physiology and evolution of delayed implantation in carnivores. [In: Carnivore behaviour, ecology, and evolution. J. L. Gittleman, ed]. Cornell University Press, New York: 437-464.

Mead R. A. 1993. Embryonic diapause in vertebrates. Journal of Experimental Zoology 266: 629-641.

Morris D. T. 1988. An evaluation of the use of texture measurements for the tissue characterisation of ultrasonic images of in vivo human placentae. Ultrasound in Medicine and Biology 14: 387-395.

Mulley R. C., English A. W., Rawlinson R. J. and Chapple R. S. 1987. Pregnancy diagnosis of fallow deer by ultrasonography. Australian Veterinary Journal 64: 257-258.

Revol B. and Wilson P. R. 1991. Ultrasonography of the reproductive tract and early pregnancy in red deer. Veterinary Record 128: 229-233.

Short R. V. and Hay M. F. 1966. Delayed implantation in the roe deer Capreolus capreolus. [In: Comparative biology of reproduction in mammals. I. W. Rowlands, ed]. Academic Press, London: 173-194. 
Skorton D. J., Collins S. M., Woskoff S. D., Bean J. A. and Melton H. E. 1983. Range- and azimuth-dependent variability of image texture in two-dimensional echocardiograms. Circulation 68 : 834-840.

Sohn C., Stolz W. and Bastert G. 1992. Erste Ergebnisse einer neuen Methode zur sonographischen Lungenreifediagnostik. Ultraschall in der Medizin 13: 37-40.

Stubbe C. 1997. Rehwild: Biologie, Ökologie, Bewirtschaftung. Parey Buchverlag, Berlin: 1-568.

Tak T., Rahimtoola S. H., Kumar A., Gamae N. and Chandraratna P. A. N. 1988. Value of digital image processing of two-dimensional echocardiograms in differentiating active from chronic vegetations of infective endocarditis. Circulation 78: 116-123.

Wilson P. R. and Bingham C. M. 1990. Accuracy of pregnancy diagnosis and prediction of calving date in red deer using real-time ultrasound scanning. Veterinary Record 126: 133-135.

Ziegler L. 1843. Beobachtungen über die Brunst und den Embryo der Rehe. Hellweg'sche Hofbuchhandlung, Hannover.

Received 10 June 1999, acceppted 17 January 2000. 